University of Wollongong

Research Online

Faculty of Engineering - Papers (Archive)

Faculty of Engineering and Information

Sciences

$1-1-2009$

\title{
In situ study of dynamic recrystallization and hot deformation behavior of a multiphase titanium aluminide alloy
}

Klaus-Dieter Liss

Australian Nuclear Science \& Technology Organisation

Thomas Schmoelzer

Montanuniversitat

Kun Yan

University of Wollongong, ky241@uow.edu.au

Mark H. Reid

University of Wollongong, mreid@uow.edu.au

Matthew Peel

4European Synchrotron Radiation Facility

See next page for additional authors

Follow this and additional works at: https://ro.uow.edu.au/engpapers

Part of the Engineering Commons

https://ro.uow.edu.au/engpapers/960

\section{Recommended Citation}

Liss, Klaus-Dieter; Schmoelzer, Thomas; Yan, Kun; Reid, Mark H.; Peel, Matthew; Dippenaar, Rian J.; and Clemens, Helmut: In situ study of dynamic recrystallization and hot deformation behavior of a multiphase titanium aluminide alloy 2009.

https://ro.uow.edu.au/engpapers/960

Research Online is the open access institutional repository for the University of Wollongong. For further information contact the UOW Library: research-pubs@uow.edu.au 


\section{Authors}

Klaus-Dieter Liss, Thomas Schmoelzer, Kun Yan, Mark H. Reid, Matthew Peel, Rian J. Dippenaar, and Helmut Clemens 


\section{AIP Applied Physics}

\section{In situ study of dynamic recrystallization and hot deformation behavior of a multiphase titanium aluminide alloy}

Klaus-Dieter Liss, Thomas Schmoelzer, Kun Yan, Mark Reid, Matthew Peel et al.

Citation: J. Appl. Phys. 106, 113526 (2009); doi: 10.1063/1.3266177

View online: $\mathrm{http}: / / \mathrm{dx}$.doi.org/10.1063/1.3266177

View Table of Contents: http://jap.aip.org/resource/1/JAPIAU/v106/i11

Published by the American Institute of Physics.

\section{Related Articles}

Temperature-induced anomalous brittle-to-ductile transition of bulk metallic glasses Appl. Phys. Lett. 99, 241907 (2011)

Role of material properties and mesostructure on dynamic deformation and shear instability in AI-W granular composites

J. Appl. Phys. 110, 114908 (2011)

A unified approach for extracting strength information from nonsimple compression waves. Part II. Experiment and comparison with simulation

J. Appl. Phys. 110, 113506 (2011)

Microstructure dependence of dynamic fracture and yielding in aluminum and an aluminum alloy at strain rates of $2 \times 106$ s1 and faster

J. Appl. Phys. 110, 103509 (2011)

Size-affected shear-band speed in bulk metallic glasses

Appl. Phys. Lett. 99, 171904 (2011)

\section{Additional information on J. Appl. Phys.}

Journal Homepage: http://jap.aip.org/

Journal Information: http://jap.aip.org/about/about_the_journal

Top downloads: http://jap.aip.org/features/most_downloaded

Information for Authors: http://jap.aip.org/authors

\section{ADVERTISEMENT}

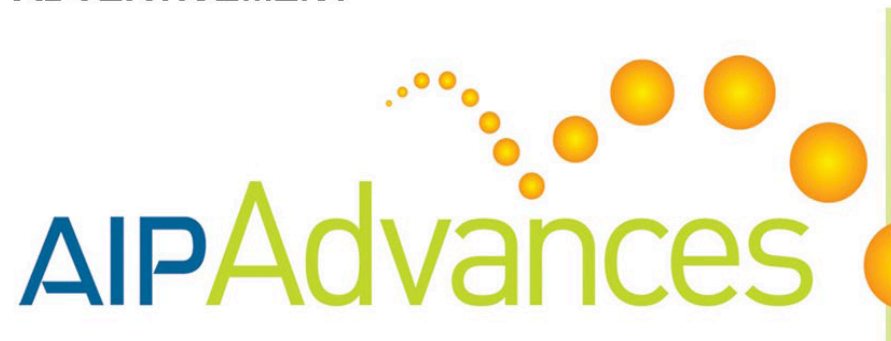

Submit Now

\section{Explore AIP's new \\ open-access journal}

Article-level metrics now available

Join the conversation!

Rate \& comment on articles 


\title{
In situ study of dynamic recrystallization and hot deformation behavior of a multiphase titanium aluminide alloy
}

\author{
Klaus-Dieter Liss, ${ }^{1, a)}$ Thomas Schmoelzer, ${ }^{2}$ Kun Yan, ${ }^{1,3}$ Mark Reid, ${ }^{3}$ Matthew Peel, ${ }^{4}$ \\ Rian Dippenaar, ${ }^{3}$ and Helmut Clemens ${ }^{2}$ \\ ${ }^{1}$ Australian Nuclear Science and Technology Organisation, PMB 1, Menai, New South Wales 2234, \\ Australia \\ ${ }^{2}$ Department of Physical Metallurgy and Materials Testing, Montanuniversität, A-8700 Leoben, Austria \\ ${ }^{3}$ Faculty of Engineering, University of Wollongong, Wollongong, New South Wales 2522, Australia \\ ${ }^{4}$ European Synchrotron Radiation Facility, BP 220, F-38043 Grenoble, France
}

(Received 14 September 2009; accepted 28 October 2009; published online 10 December 2009)

\begin{abstract}
Hot-compression tests were conducted in a high-energy synchrotron $\mathrm{x}$-ray beam to study in situ and in real time microstructural changes in the bulk of a $\beta$-solidifying titanium aluminide alloy. The occupancy and spottiness of the diffraction rings have been evaluated in order to access grain growth and refinement, orientation relationships, subgrain formation, dynamic recovery, and dynamic recrystallization, as well as phase transformations. This method has been applied to an alloy consisting of two coexisting phases at high temperature and it was found that the bcc $\beta$-phase recrystallizes dynamically, much faster than the hcp $\alpha$-phase, which deforms predominantly through crystallographic slip underpinned by a dynamic recovery process with only a small component of dynamic recrystallization. The two phases deform to a very large extent independently from each other. The rapid recrystallization dynamics of the $\beta$-phase combined with the easy and isotropic slip characteristics of the bcc structure explain the excellent deformation behavior of the material, while the presence of two phases effectively suppresses grain growth. (C) 2009 American Institute of Physics. [doi:10.1063/1.3266177]
\end{abstract}

\section{INTRODUCTION}

A sound understanding of plastic deformation and recrystallization in metals and intermetallics is a necessary prerequisite for the design and processing of materials with novel or improved physical properties like mechanical strength, heat resistivity, ductility, formability, and so on. For example, it is desirable to develop intrinsically lighter and stronger materials for the transportation and aerospace industry, thereby reducing propulsion and energy costs. Intermetallic titanium aluminides are in the focus of research as they show enhanced mechanical strength at elevated temperatures and as such are good candidates to replace the heavy nickel based superalloys in specific components of aero- and automotive engines. ${ }^{1-3}$ Although titanium aluminides exhibit attractive mechanical properties, they are not widely used due to difficult and expensive manufacturing routes. ${ }^{3-5}$ This is, in large part, a consequence of the complex phase diagram of these alloys, possessing different regions of atomic order/ disorder leading to different properties of the constituent phases. On the other hand, it is the form of the phase diagram that determines the strength of this type of material. At the intended application temperatures of 870-1020 K, simple TiAl based alloys exhibit a dual phase field of ordered hcp $\alpha_{2}-\mathrm{Ti}_{3} \mathrm{Al}\left(\mathrm{D}_{19}\right)$ and near- $f c c \quad \gamma$-TiAl $\left(\mathrm{L}_{0}\right)$ structures. The $\alpha_{2}$-phase disorders at the eutectoid temperature $\sim 1453 \mathrm{~K}$ into hcp $\alpha$, whereas the $\gamma$-phase disappears at the $\alpha$-transus temperature of typical $T_{\alpha} \sim 1573 \mathrm{~K}$. Accurate temperature values depend on the exact composition. It has been found

a)Electronic mail:kdl@ansto.gov.au and liss@kdliss.de. that successful plastic deformation can be performed only in a narrow temperature range in the $\alpha+\gamma$ phase field. ${ }^{4}$ In this narrow "deformation window," phase fractions vary strongly with temperature, ${ }^{6}$ and it is difficult to control the hotworking process. ${ }^{4,5}$ Deformation can also be performed above the $\alpha$-transus, but this leads to crystalline anisotropy of the hexagonal system and the associated texture formation. In addition, rapid grain growth occurs at these temperatures, thereby excluding this temperature range for production purposes. To circumvent these drawbacks, an approach is taken whereby the bcc $\beta$-Ti phase is stabilized at high temperatures, which is known to both deform easily and show less anisotropy than the hcp $\alpha$-Ti phase. ${ }^{7}$ A single $\beta$-phase field region at high temperature is not desired because of grain coarsening. ${ }^{8}$ In order to overcome these problems, the so-called $\mathrm{TNM}^{\mathrm{TM}}$ alloy of nominal composition Ti43.5Al-4Nb-1Mo-0.1B (composition in atomic percent) was developed. ${ }^{9}$ The alloy solidifies through the $\beta$-phase and exhibits a wide $\alpha+\beta$-phase field in which hot-working can be conducted on an industrial scale. For example, an excellent forgeability in the $\alpha+\beta$-phase field has been reported. ${ }^{10}$ The phase diagram for TNM alloy was established ${ }^{11}$ and refined recently by in situ neutron diffraction. ${ }^{12}$ In situ hightemperature laser scanning confocal microscopy proved the slow kinetics of grain growth in the high temperature $\alpha+\beta$ phase field region, ${ }^{12}$ where the material is soft and ductile. A more comprehensive account of TNM alloys is given by Clemens and co-workers. ${ }^{9,10,13}$

The aim of the present study is to obtain in situ and in real time information from the bulk of the Ti-43.5Al-4Nb$1 \mathrm{Mo}-0.1 \mathrm{~B}$ alloy during hot compression. The starting poly- 
crystalline microstructure consists of lamellar $\gamma / \alpha_{2}$ colonies with globular $\gamma$-grains and ordered $\beta_{0}$-grains containing $\gamma$-precipitates with a grain size of about $100 \mu \mathrm{m}$. The recently developed high-energy synchrotron x-ray diffraction method $^{14}$ combined with the evaluation of the morphology of the diffraction Debye-Scherrer rings ${ }^{15,16}$ is applied to a multiphase alloy undergoing hot plastic deformation. This allows the evaluation of grain size statistics ${ }^{17}$ such as growth and refinement, subgrain formation, ${ }^{18}$ lattice strain, ${ }^{19}$ grain orientations, orientation relationships between grains and phases, ${ }^{20}$ grain rotations, ${ }^{21}$ texture evolution, ${ }^{16}$ mechanisms of phase transformations, ${ }^{22}$ dynamic recovery, and dynamic recrystallization. $^{15}$

\section{EXPERIMENTAL}

The experiment was performed at the beamline ID15b of the European Synchrotron Radiation Facility (ESRF) ${ }^{14,23}$ using high-energy $\mathrm{x}$-rays of $86.94 \mathrm{keV}$ corresponding to an incident wave number $k=44.03 \AA^{-1}$ and wavelength $\lambda=0.1427 \AA$. The $\varnothing \sim 100 \mu \mathrm{m}$ beam transmits the $\varnothing 4 \mathrm{~mm}$ sample and is diffracted from its crystallites into DebyeScherrer rings on a detector in $1233.8 \mathrm{~mm}$ distance from the sample center. The relatively small number of crystallites in the illuminated volume leads to spottiness on the DebyeScherrer rings, which should be avoided in conventional powder diffraction but plays an essential role in the present investigation. The fast Pixium 4700 flat-panel detector ${ }^{24}$ was employed for real time data acquisition at $\sim 2 \mathrm{~Hz}$. The wirecut, $4 \mathrm{~mm}$ diameter, $8 \mathrm{~mm}$ high cylindrical sample was deformed in an Instron electrothermomechanical tester for simulating thermomechanical processing. In the present configuration, loads up to $3000 \mathrm{~N}$ can be applied while the specimen is heated resistively with a maximum power angle of $8 \mathrm{~V}$ and $450 \mathrm{~A}$. Dedicated high-temperature compression anvils were produced from a special molybdenum alloy (TZM). In addition, graphite and tantalum foils were inserted between the anvil faces and the sample. This arrangement assured good electric contact, provided lubrication between the sample and anvil (graphite), and prevented diffusion of carbon into the specimen (tantalum). The load axis was horizontally perpendicular to the incident beam and translation scans have been taken to align accurately the center of the sample with the center of the beam. A regulation loop was implemented to keep the centers in coincidence during compression before any diffraction image was taken. The mean detector distance was calibrated by recording two diffraction patterns in different distances and using triangulation, while the x-ray energy was calibrated with a $\mathrm{CeO}_{2}$ standard. The process parameters were a heat ramp of $9.5 \mathrm{~K} / \mathrm{s}$ up to the maximum temperature of $1573 \mathrm{~K}$ after $145 \mathrm{~s}$. This temperature was chosen to ensure the compatibility of the results to the findings published in Ref. 10. After $35 \mathrm{~s}$ hold, a constant compression rate of $0.021 \mathrm{~mm} / \mathrm{s}$ was applied (strain rate of $\left.\sim 2.6 \times 10^{-3} \mathrm{~s}^{-1}\right)$. After compressing for $45 \mathrm{~s}(\sim 1 \mathrm{~mm}$, $12.5 \%$ strain), the deformation was interrupted for $22 \mathrm{~s}$ in order to study relaxation. Compression was then continued and after a further $153 \mathrm{~s}(\sim 4.15 \mathrm{~mm}, 52 \%$ strain $)$ when the applied load was $410 \mathrm{~N}$, the temperature regulation system

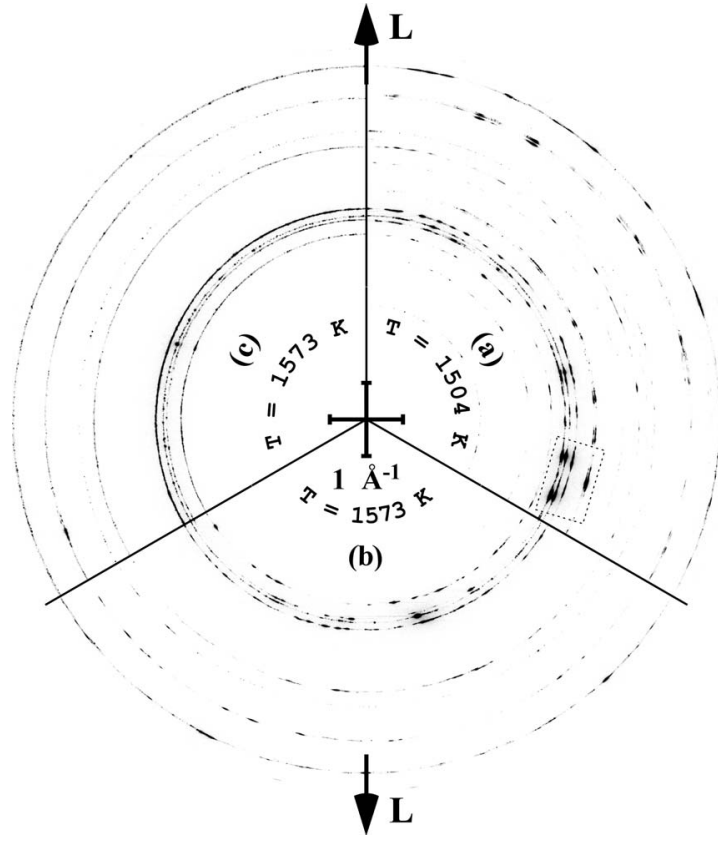

FIG. 1. Representative parts of the acquired diffraction rings compiled in three sectors: (a) below the alpha transus temperature $T_{\alpha}$, showing $\alpha-, \beta-$, and $\gamma$-phases in coexistence; (b) above $T_{\alpha}$, where $\gamma$ disappeared before plastic deformation and (c) above $T_{\alpha}$ during plastic deformation. Reflections in the indicated box in (a) reveal orientation correlations of all three phases. The common ring center is marked with a crossed scale bar of $1 \AA^{-1}$ and the longitudinal load direction $L$ is indicated. Reflections are indexed in Fig. 2 .

became unstable (maximum power reached due to the increasing cross section of the sample) and the temperature began to drop resulting in the applied load increasing rapidly to $1103 \mathrm{~N}$ some $40 \mathrm{~s}$ later. At this time, the machine safety tripped and the jaws rapidly returned to their starting positions loosing the sample from the beam. The temperature was measured by a R-type thermocouple spot welded on the central circumference of the cylinder outside the beam cross section.

\section{RESULTS AND DISCUSSION}

Figure 1 shows experimentally obtained diffraction patterns as an assembly of three sectors (a) at $T=1504 \mathrm{~K}$, below the $\alpha$-transus temperature $\left(T_{\alpha}=1555 \mathrm{~K}\right),(\mathrm{b})$ above $T_{\alpha}$, before and (c) during deformation $[T=1573 \mathrm{~K}$ for both (b) and (c)]. The reflections are indexed in Fig. 2, which represents, in color scale, the azimuthally integrated diffraction rings against the scattering vector (radial direction of the rings) and time. The experimental parameters are depicted on the same time axis to the right of the graph. The pattern at $1504 \mathrm{~K}$ in Fig. 1(a) shows rings stemming from all three coexistent phases, $\alpha, \beta$, and $\gamma$. The $\gamma$-TiAl phase disappears at $T_{\alpha}$ and only reflections from the $\alpha$-and $\beta$-phase remain in the $1573 \mathrm{~K}$ sectors (b) and (c). There are also correlations between the $\alpha-, \beta$-, and $\gamma$-reflections expressed by intensity agglomerations at equal or nearby azimuthal angles, confirming the Blackburn orientation correlation between $\alpha$ - and $\gamma$-phase in Fig. 1(a) (Refs. 20 and 25), as well as the Burgers orientation correlation between $\alpha$ - and $\beta$-phase in Figs. 1(a) and 1(b). ${ }^{15,26}$ Additionally, the box in Fig. 1(a) shows the 


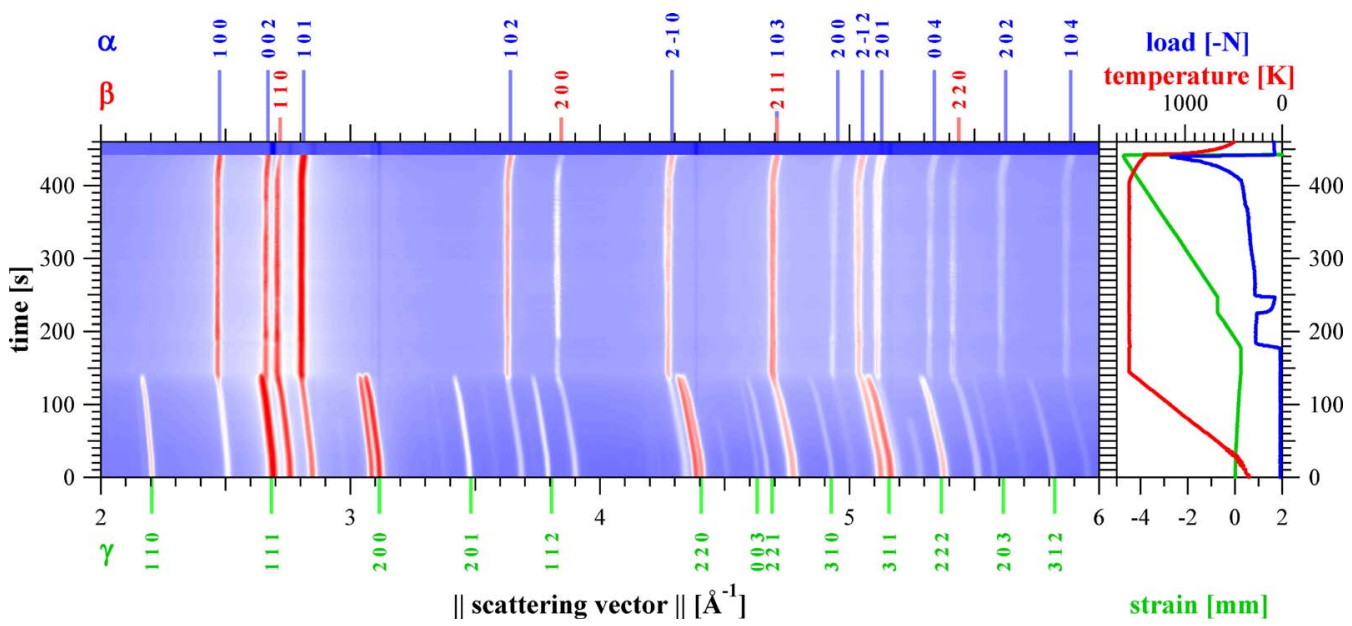

FIG. 2. (Color online) Color coded powder diffraction patterns obtained by azimuthal integration of the time frames in Fig. 1 vs scattering vector $q=4 \pi / \lambda \sin (2 \theta / 2)$ on the abscissa evolving in time on the ordinate to the left. Because of the tetragonality of $\gamma$-TiAl ( $\mathrm{L}_{0}$ structure), some reflections appear as double lines. For simplification, however, indices are given for a $f c c$ lattice. The deformation parameters (compressive mode) are given to the right.

orientation correlations between all three phases where the $\gamma-002 / 200$ spot aligns in a triangle with $\alpha-101, \beta-110$, and $\alpha-002{ }^{22}$ The time evolution of the azimuthally integrated patterns in Fig. 2 shows the effect of thermal expansion, moving the reflections to smaller scattering vectors upon heating. There are some weak superstructure reflections disappearing halfway through the heating ramp, which correspond to the ordered $\alpha_{2}$ and $\beta_{0}$ phases. $^{12}$ The disappearance of the $\gamma$-TiAl phase determines the $\alpha$-transus temperature which was determined as $T_{\alpha}=1555 \mathrm{~K}$ in agreement with earlier reported values. ${ }^{12,13}$ This good agreement provides convincing experimental evidence of the accuracy of the present experiment.

The data is represented in Fig. 3, where the intensity distribution along a certain diffraction ring is plotted in grayscale as a function of azimuthal angle and time. To produce this representation of the diffraction data, the full circle of a Debye-Scherrer ring from Fig. 1 is cut at the six o'clock position and straightened into one horizontal line from 0 to $360^{\circ}$ of Fig. 3 at any given time. A $20^{\circ}$ cyclic extension is plotted at either side of the range in order to evaluate features in this orientation range. Directions longitudinal $(L)$ and transverse $(T)$ to the load axis are indicated at the top of the figure. The vertical time axis is the same as in Fig. 2 and the experimental parameters are reproduced for reference. The azimuthal-angle-time plots (AT-plots) allow the time evolution of reflections in orientation space to be tracked. In principle, each line is a one-dimensional manifold section from a conventional pole figure. ${ }^{16}$ When not overlapping, the number of spots on a selected ring at any one time represents the number of crystallites matching the Ewald sphere for the Laue condition. Therefore, in the case of a fixed illuminated volume, the number of spots is somehow inversely proportional to the crystallite size raised to a certain power for multiple dimensions. Further, a sharp reflection stemming from a perfect crystallite has a lower probability of hitting the Ewald sphere than a broad reflection with large mosaic spread evolving from lattice distortions such as dislocations and subgrain cells. In short, the number of diffraction spots increases with smaller grain size and larger mosaic spread. In addition to these microstructural parameters, symmetry plays a role for the number of observable spots, and, hence, it is also proportional to the multiplicity of the reflections. The evolution of an individual reflection spot in the AT-plot is called a timeline. Particular features of timelines are shown in Fig. 4 as zoomed regions of interest extracted from Fig. 3.

Considering first the heating part of the experimental cycle, apart from minor intensity changes, AT-plots of the $\alpha$-phase in Fig. 3 stay very stable until the $\alpha$-transus is reached. This implies that there is no major evolution in grain size nor in mosaic spread and the overall microstructure remains intact. While the $\gamma-111$ timelines disappear at $T_{\alpha}$, the $\alpha$-reflections augment intensity due to the increase of the total phase fraction of $\alpha$-Ti and there is no further evolution of the morphology. The number of timelines observed in the individual reflections corresponds well to the ratio of their multiplicities which are 6,2, 12 for $\alpha$-100, $\alpha$-002, and $\alpha-101$, and 12,6 for $\beta-110$ and $\beta-200$, respectively. This can be best viewed after the $\gamma$-phase disappeared in Fig. 3, for example, by regarding a cut at time $160 \mathrm{~s}$ and statistically counting the number of intensity maxima.

The $\beta$-phase behaves differently upon approaching $T_{\alpha}$ and holding at a temperature just above $T_{\alpha}$. The timelines sharpen and become spotty and interrupted and their overall distribution diminishes, meaning the density of Bragg spots fluctuates and shrinks. This can be interpreted as a grain recovery process and sharpening of mosaic spread. The driving force for this process is probably due to transformation induced stresses. As the temperature was raised quickly with respect to the transformation kinetics of the system, on-going rearrangements of the $\alpha$ - and $\beta$-phases take place, particularly influencing the minority $\beta$-phase. ${ }^{9,10}$

Considering the deformation part of the experimental cycle on the $\beta$-phase, upon the onset of plastic deformation at $t=180 \mathrm{~s}$, timelines of the $\beta$-phase spread out rapidly into a larger angular range, which can be recognized, for example, on the intense timelines around azimuth $\psi=280^{\circ}$ and $\psi=290^{\circ}$ on the AT-plots of $\beta-110$. Other outbursts in orientation space seem to occur at angular positions where previously no or little intensity was observed, such as at 


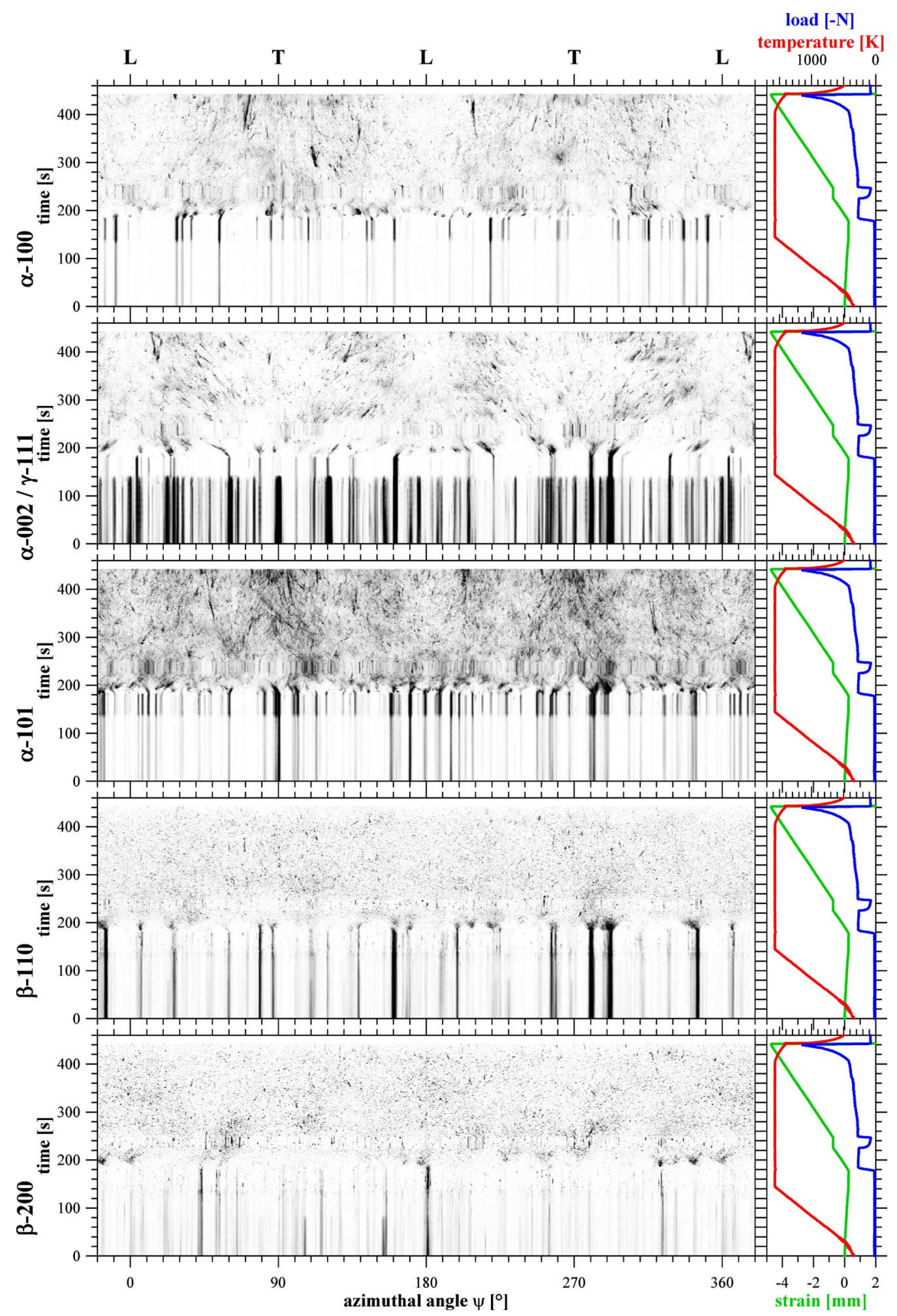

FIG. 3. (Color online) AT-plots of the first three $\alpha$-and two $\beta$-reflections. The $\alpha-002$ and $\gamma$-111 reflections overlap and cannot be separated until the $\gamma$-phase disappears at the $\alpha$-transus temperature. The orientations of the grains evolve rapidly upon the application of strain but are otherwise stable, as indicted by the deformation parameters to the right of each plot. Longitudinal and transverse load directions, $L$ and $T$, respectively, are given at the top of the azimuthal-angle axis. Zoomed regions of interest are shown in Fig. 4.

$\psi=340^{\circ}$ on $\beta-200$, as emphasized in Fig. 4(c). During the cold deformation of a metal, these broadenings stem from the breakdown of grains into subgrains with a continuous mosaic spread ending up in grain refinement and deformation texture of the material. ${ }^{16}$ The appearance of the outbursts from apparently nothing are the evolution of mosaic spread from grain orientations nearby, but not matching the Ewald sphere, which moves into the reflection condition as their angular distribution broadens. ${ }^{16}$ Upon hot deformation, however, dynamic recovery concurs with the grain breakdown forming a spotty mosaic distribution: Agglomeration of distorted subgrains recover to more perfect subgrains 

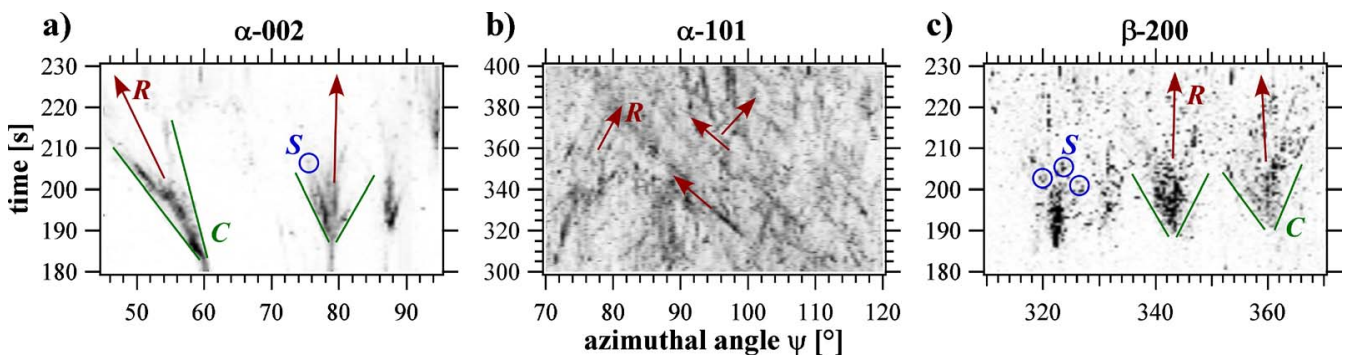

FIG. 4. (Color online) Extracts from the AT-plots of Fig. 3, showing typical features of timelines. A conical shape $\boldsymbol{C}$ represents an increase of mosaic spread caused by angular broadening through subgrain formation. The mean inclination $\boldsymbol{R}$ of the timeline characterizes grain rotation. Timelines may appear spotty, $S$, due to recovery of subgrains and their fluctuations. Predominant slip deformation, crossing of rotation vectors and strong initial dynamic recovery effects are demonstrated in (a), (b), and (c), respectively.

which are then separated by a subgrain boundary representing a small-angle boundary. ${ }^{15}$ Soon after subgrain formation, the intensity is spread all over the rings, and, hence, grains and subgrains cannot be distinguished any longer. Dynamic recrystallization, a process in which new grains, separated by large-angle boundaries, are formed from a highly distorted microstructure, is experimentally observed by the popping up and disappearance of reflections. ${ }^{15}$ Some of the short timelines show fluctuations of dynamic recovery aligned in strings which are inclined in the AT-plot due to a grain rotation process. ${ }^{16}$ Sometimes, regions of slightly preferred orientation occur on a $10^{\circ}$ scale in azimuthal angle, which indicates that there is an underpinning orientational preference upon dynamic recrystallization. ${ }^{15}$ The global texture of the $\beta$-phase, however, is very weak.

Recovery and recrystallization during deformation are considerably slower in the $\alpha$-phase than in the $\beta$-phase. Upon the onset of plastic deformation, the creation of mosaic spread behaves much smoother, almost as observed in cold deformed copper, ${ }^{16}$ as seen in Fig. 4(a). Although it occurs, dynamic recovery is strongly reduced, and large grain rotations expressed by tilted timelines occur throughout a slip deformation process. There is a high degree of preferred orientation at the end of the experiment: The prismatic $\alpha-100$ orientation distribution peaks in the $T$ directions and has a minimum along $L$, while the basal $\alpha-002$ orientation has minima at $T$ and $L$ peaking at $L \pm 35^{\circ}$, indicating a tilted basal fiber texture. ${ }^{27}$ Grains initially in arbitrary orientations rotate into these preferred orientations. As an example, the timeline starting at $\psi=60^{\circ}$ of $\alpha$-002 rotates strongly to the left [Fig. 4(a)] and the one at $\psi=120^{\circ}$ to the right, in a symmetric way away from $T$. A timeline starting close to the texture maximum or minimum orientations does not show rotation but large angular spreading as can be seen at $\psi=25^{\circ}$ and $\psi=79^{\circ}$ [Fig. 4(a)] in $\alpha-002$ or in the $T$ and $L$ directions in $\alpha-100$. The $\alpha$-101 orientation exposes high multiplicity and has components of both basal and prismatic orientations. Therefore, the inclination of the timeline depends on which of the equivalent slide systems are activated and thus can rotate this particular reflection plane, which is an inclined projection of the simple rotation vector into the left or right direction. This leads to over-crossing timelines, as seen, for example, in Fig. 4(b). Similar timeline crossings are seen occasionally in $\alpha-100$ and $\alpha-110$, but less in $\alpha-002$, indicating that $\alpha-002$ has a rotation axis along the beam axis and the basal slip system is well activated. The tilted basal fiber texture is another indication for slip deformation as deformation dominated by twinning would drive the texture maximum into the $L$ direction. Other than in the cold deformation process, ${ }^{16}$ dynamic recovery takes place when the mosaic spread becomes too large or when grain rotation takes place at a particularly high rate. The widely spread subgrains then become new, perfect grains by themselves which subsequently deform and rotate independently in the polycrystalline matrix. Highly uncorrelated dynamic recrystallization plays a minor role in the deformation of the $\alpha$-phase. Indeed, dynamic recovery in commercial pure titanium has been suggested as a dominant deformation process under certain conditions. ${ }^{28}$

The different behavior of the $\alpha$ - and $\beta$-phases is demonstrated as well in the holding cycle starting at time $225 \mathrm{~s}$, where the displacement was stopped for $22 \mathrm{~s}$. The timelines of the $\alpha$-phase remain mostly static while the $\beta$-phase still shows many fluctuations. The observed behavior is attributed to a relaxation effect, as seen in the load curve in Fig. 3, occurring mostly in the $\beta$-phase.

\section{CONCLUSION}

In conclusion, we have followed in situ and in real time the plastic deformation in the bulk of an advanced intermetallic Ti-43.5Al-4Nb-1Mo-0.1B alloy at $1573 \mathrm{~K}$. The recently developed combination of rapid two-dimensional high energy x-ray diffraction with advanced analysis of the spottiness of the diffraction rings has been presented and applied to the investigation of a multiphase alloy. Orientation relationships between the phases were identified upon static heating indicating at least three different components, namely, the Blackburn orientation correlation between the $\alpha$ and the $\gamma$-phase typical for $\gamma$-based titanium aluminides, ${ }^{25}$ the Burgers orientation correlation occurring in hcp $\leftrightarrow$ bcc transformations ${ }^{26}$ and a recently reported orientation correlation between the $\alpha-002, \alpha-101$, and $\gamma-002 / 200$ reflections. ${ }^{22}$ The hcp $\alpha$-phase deforms preferentially by slip rather than by twinning, superimposed by a relatively slow dynamic recovery and a less important dynamic recrystallization process. This leads to a tilted basal fiber deformation texture. In contrast, the bcc $\beta$-phase is driven by rapid fluctuations in orientation space, which start below the $\alpha$-transus temperature during heating and continue during holding at the defor- 
mation temperature before the compression test is started. The high activity of the $\beta$-phase gives raise to rapid dynamic recovery and dynamic recrystallization which basically overwrites almost any deformation texture of this phase. It is interesting to note that there is no major coupling between the orientations and the deformation processes of the $\alpha$ - and the $\beta$-phase, and it appears that each grain behaves individually, self-consistently in a polycrystalline matrix. The coexistence of $\alpha$ - and $\beta$-phases hinders rapid grain growth as opposed to that observed in alloys with a single-phase field. The high rate of dynamic recovery and recrystallization occurring within $\beta$-grains render TNM alloys favorable for thermomechanical processing.

\section{ACKNOWLEDGMENTS}

The Australian participants acknowledge travel funding provided by the International Synchrotron Access Program (ISAP) managed by the Australian Synchrotron. The ISAP is funded by a National Collaborative Research Infrastructure Strategy grant provided by the Federal Government of Australia. We also appreciate the access and support of the ESRF management, User Office, and beamline staff. The European experimentalist wishes to express thanks for the ESRF travel support. Sample materials were provided by GfE Metalle und Materialien $\mathrm{GmbH}$, Nuremberg, Germany and Bohler Schmiedetechnik GmbH \& CoKG, Kapfenberg, Austria. The authors thank Wilfried Wallgram for helpful discussions.

${ }^{1}$ E. A. Loria, Intermetallics 8, 1339 (2000).

${ }^{2}$ W. Smarsly, H. Baur, G. Glitz, H. Clemens, T. Khan, and M. Thomas, "Titanium Aluminides for Automotive and Gas Turbine Applications," in Structural Intermetallics, edited by K. J. Hemker, D. M. Dimiduk, H. Clemens, R. Darolia, H. Inui, J. M. Larsen, V. K. Sikka, M. Thomas, and J. D. Whittenberger (The Minerals, Metals and Materials Society, Warrendale, 2001), pp. 25-34.

${ }^{3} \mathrm{X}$. H. Wu, Intermetallics 14, 1114 (2006).

${ }^{4}$ S. Kremmer, H. F. Chladil, H. Clemens, A. Otto, and V. Güther, in Ti-2007 Science and Technology, edited by M. Niinomi, S. Akiyama, M. Hagiwari, M. Ikeda, and K. Maruyama (The Japan Institute of Metals, Sendai, 2007), pp. 989-992.

${ }^{5}$ F. Appel and M. Oehring, in Titanium and Titanium Alloys, edited by C. Leyens and M. Peters (Wiley-VCH, Weinheim, 2003), pp. 89-152.
${ }^{6}$ L. A. Yeoh, K.-D. Liss, A. Bartels, H. F. Chladil, M. Avdeev, H. Clemens, R. Gerling, and T. Buslaps, Scr. Mater. 57, 1145 (2007).

${ }^{7}$ A. Stark, A. Bartels, R. Gerling, F. P. Schimansky, and H. Clemens, Adv. Eng. Mater. 8, 1101 (2006).

${ }^{8}$ D. Phelan, M. Reid, N. Stanford, and R. Dippenaar, JOM 58, 67 (2006).

${ }^{9}$ H. Clemens, W. Wallgram, S. Kremmer, V. Guther, A. Otto, and A. Bartels, Adv. Eng. Mater. 10, 707 (2008).

${ }^{10}$ W. Wallgram, T. Schmölzer, L. Cha, G. Das, V. Güther, and H. Clemens, Int. J. Mater. Res. 8, 1021 (2009).

${ }^{11}$ H. Clemens, B. B. Böck, W. Wallgram, T. Schmölzer, L. M. Drössler, G. A. Zickler, H. Leitner, and A. Otto, Mater. Res. Soc. Symp. Proc. 1128, 451 (2009)

${ }^{12}$ I. J. Watson, K. D. Liss, H. Clemens, W. Wallgram, T. Schmoelzer, T. Hansen, and M. Reid, Adv. Eng. Mater. 11, 932 (2009).

${ }^{13}$ H. Clemens, H. F. Chladil, W. Wallgram, G. A. Zickler, R. Gerling, K. D. Liss, S. Kremmer, V. Guther, and W. Smarslyg, Intermetallics 16, 827 (2008).

${ }^{14}$ K.-D. Liss, A. Bartels, A. Schreyer, and H. Clemens, Textures Microstruct. 35, 219 (2003).

${ }^{15}$ K.-D. Liss, U. Garbe, H. Li, T. Schambron, J. D. Almer, and K. Yan, Adv. Eng. Mater. 11, 637 (2009).

${ }^{16}$ K. Yan, K.-D. Liss, U. Garbe, J. Daniels, O. Kirstein, H. Li, and R. Dippenaar, Adv. Eng. Mater. 11, 771 (2009).

${ }^{17}$ S. E. Offerman, N. H. Van Dijk, J. Sietsma, S. Grigull, E. M. Lauridsen, L. Margulies, H. F. Poulsen, M. T. Rekveldt, and S. Van Der Zwaag, Science 298, 1003 (2002).

${ }^{18}$ B. Jakobsen, H. F. Poulsen, U. Lienert, J. Almer, S. D. Shastri, H. O. Sorensen, C. Gundlach, and W. Pantleon, Science 312, 889 (2006).

${ }^{19}$ J. Böhm, A. Wanner, R. Kampmann, H. Franz, K.-D. Liss, A. Schreyer, and H. Clemens, Nucl. Instrum. Methods Phys. Res. B 200, 315 (2003).

${ }^{20}$ K.-D. Liss, A. Bartels, H. Clemens, S. Bystrzanowski, A. Stark, T. Buslaps, F.-P. Schimansky, R. Gerling, C. Scheu, and A. Schreyer, Acta Mater. 54, 3721 (2006).

${ }^{21}$ L. Margulies, G. Winther, and H. F. Poulsen, Science 291, 2392 (2001).

${ }^{22}$ K. D. Liss, A. Stark, A. Bartels, H. Clemens, T. Buslaps, D. Phelan, and L. A. Yeoh, Adv. Eng. Mater. 10, 389 (2008).

${ }^{23}$ T. Tschentscher and P. Suortti, J. Synchrotron Radiat. 5, 286 (1998).

${ }^{24}$ J. E. Daniels and M. Drakopoulos, J. Synchrotron Radiat. 16, 463 (2009).

${ }^{25} \mathrm{M}$. J. Blackburn, in The Science, Technology and Application of Titanium, edited by R. I. Jaffee and N. E. Promisel (Pergamon Press Ltd., Oxford, 1970), p. 633-643.

${ }^{26}$ W. G. Burgers, Physica (Amsterdam) 1, 561 (1934).

${ }^{27}$ A. Stark, A. Bartels, F.-P. Schimansky, and H. Clemens, in Advanced Intermetallic-Based Alloys, edited by Jörg Wiezorek, Chong Long Fu, Masao Takeyama, David Morris, and Helmut Clemens (Mater. Res. Soc. Symp. Proc. 980, Warrendale, PA, 2007), 0980-II07-01.

${ }^{28}$ Z. P. Zeng, Y. S. Zhang, and S. Jonsson, Mater. Sci. Eng., A 513-14, 83 (2009). 